\title{
Comércio informal e formal de alimentos no âmbito escolar de um município da região central do Rio Grande do Sul
}

\author{
Informal and formal food trade in the school environment in a city in the central region \\ of Rio Grande do Sul, Brazil
}

\section{Simone de Castro Giacomelli ${ }^{1 *}$, Aline de Moraes Londero², Franceliane Jobim Benedetti ${ }^{2}$, Ana Lúcia de Freitas Saccol ${ }^{2}$}

${ }^{1}$ Universidade Federal de Santa Catarina (UFSC), Departamento de Nutrição, Florianópolis/SC - Brasil

${ }^{2}$ Centro Universitário Franciscano (UNIFRA), Curso de Nutrição, Santa Maria/RS - Brasil

\section{*Corresponding Author}

Simone de Castro Giacomelli, Universidade Federal de Santa Catarina (UFSC), Departamento de Nutrição, Campus Universitário Trindade, CEP: 88040-900, Florianópolis/SC - Brasil, e-mail: scgiacomelli@yahoo.com.br

Cite as: Informal and formal food trade in the school environment in a city in the central region of Rio Grande do Sul, Brazil. Braz. J. Food Technol., v. 20, e2016136, 2017.

\section{Resumo}

O objetivo deste estudo foi avaliar o comércio de alimentos nas escolas, tanto o comércio informal quanto em cantinas. O trabalho transcorreu de março a maio de 2011, de um universo de 110 escolas de Ensino Fundamental e Ensino Médio das redes municipal, estadual e privada de um município da região central do Estado do Rio Grande do Sul. Das 110 escolas, 104 (94,5\%) participaram da pesquisa e, destas, 28,8\% possuíam cantina, sendo uma presença marcante nas escolas privadas. Das escolas que não possuíam cantina, 40,4\% possuíam comércio informal, sendo a maioria formada por escolas do âmbito municipal. Nas cantinas, há maior oferta de salgados fritos e folhados, cachorros-quentes, pizzas, hambúrgueres, balas, chicletes e pirulitos, refrigerantes, sucos industrializados e água. Os alimentos mais vendidos são salgados fritos, assados, cachorros-quentes, balas, chocolates e refrigerantes, em todos os âmbitos. Em suma, pode-se concluir que nenhuma cantina escolar está totalmente adequada em relação à lei vigente; porém, as cantinas das escolas particulares apresentam resultados mais satisfatórios quando comparadas às dos outros âmbitos.

Palavras-chave: Alimentação escolar; Doces; Legislação sobre alimentos; Políticas públicas; Refrigerantes.

\section{Abstract}

The objective of this study was to evaluate the trading of food in schools, both informally and in canteens. The study was carried out from March to May 2011, in a universe of 110 elementary and middle schools of the municipal, state and private networks of a municipality in the central region of the State of Rio Grande do Sul, Brazil, of which 104 (94.5\%) took part in the survey; $28.8 \%$ had a canteen, with a marked presence in the private schools. Of the schools that had no canteen, $40.4 \%$ had informal ways of food trading, mostly in the municipal schools. In the canteens there was a greater supply of fried snacks and pastries, hot dogs, pizzas, burgers, candy, chewing gum and lollipops, sodas, processed juices and water. The foods most sold in all the environments were fried goods, baked goods, hot dogs, candies, chocolates and soft drinks. In summary one can conclude that no school canteen conformed in full to current law, but the canteens of the private schools were more satisfactory than those in the other schools.

Keywords: School feeding; Candy; Food legislation; Public policies; Soft drinks. 


\section{Introdução}

A promoção de práticas alimentares saudáveis no âmbito escolar, como a regulamentação do comércio de alimentos nas cantinas escolares, são ações recomendadas pela Organização Mundial da Saúde (OMS) e pelo Ministério da Saúde, através do manual das cantinas escolares saudáveis (WHO, 2004; BRASIL, 2010a).

No Brasil, ressalta-se a Portaria Interministerial n. ${ }^{\circ} 1.010$ de 2006, pelos Ministérios da Saúde e da Educação, que instituiu as diretrizes para a Promoção da Alimentação Saudável nas escolas. Essa Portaria recomenda a restrição ao comércio e à promoção comercial de alimentos e preparações com altos teores de gordura saturada, gordura trans, açúcar livre e sal, e incentiva o consumo de frutas, legumes e verduras, no ambiente escolar (BRASIL, 2006). Neste contexto, a cantina é uma dependência, dentro do estabelecimento de ensino, designada a fornecer serviços de alimentação a alunos, professores e funcionários, mediante pagamento (SÃO PAULO, 2005), e esta é apenas uma das maneiras pelas quais os alimentos podem ser disponibilizados nas escolas. Salientam-se, ainda, a alimentação escolar, o comércio informal de alimentos e os lanches levados de casa.

Nesta perspectiva, em agosto de 2008 , foi promulgada a Lei n. ${ }^{\circ}$ 13.027, que dispõe sobre a comercialização de lanches e bebidas em escolas no âmbito do Estado do Rio Grande do Sul, sendo que este comércio realizado em escolas deverá atender essencialmente ao perfil de produtos e de serviços que visem à saúde dos alunos. Determina ainda que as cantinas ofereçam frutas, sanduíches, sucos e saladas naturais em maior evidência que os demais alimentos. Veta a exposição de cartazes publicitários que estimulem o consumo de balas, chicletes, salgadinhos e refrigerantes. Exige a fixação, em local visível, de painel informativo tratando de assuntos relacionados com a qualidade nutricional dos alimentos e o alvará sanitário expedido pelo órgão competente. Menciona ainda às qualidades higiênico-sanitária e nutricional dos produtos comercializados, sendo que os proprietários das cantinas devem garanti-las (RIO GRANDE DO SUL, 2008).

Outros Estados e municípios possuem estratégias semelhantes de regulamentação das cantinas escolares, como nos municípios de Belo Horizonte (2003), Florianópolis (2001), Natal (2006), Porto Alegre (2007), Ribeirão Preto (2002) e Rio de Janeiro (2002), bem como nos Estados Paraná (2004, 2005), Rio de Janeiro 2005) e Santa Catarina (2001), e na rede pública do Estado de São Paulo (2005). Avalia-se ainda que, como não há proibição para o comércio de alimentos nas escolas, deve existir uma sintonia entre esses comércios e os preceitos preconizados pelo Programa Nacional de Alimentação Escolar (PNAE), o qual agrega uma importante estratégia de promoção de hábitos alimentares saudáveis nas escolas públicas. Para Zancul e Dal Fabro (2007), é importante analisar o tipo de alimentação oferecida aos alunos, para elaboração de estratégias de intervenção que visem à prevenção de doenças.

Portanto, o objetivo do presente estudo foi avaliar o comércio informal e formal de alimentos em escolas de um município da região central do Estado do Rio Grande do Sul.

\section{Metodologia}

A pesquisa apresenta delineamento observacional transversal, realizada com gestores e cantineiros de escolas localizadas nas áreas urbana e rural, em um município da região central do Estado do Rio Grande do Sul (RS), Brasil, no período de março a maio de 2011

Foram convidadas a participar do estudo todas as escolas de Ensino Fundamental e Ensino Médio, das redes municipal, estadual e privada. Conforme o censo escolar de 2010, realizado pelo Setor de Estatística da Secretaria da Educação do Rio Grande do Sul, havia, no município, 110 escolas de Ensino Fundamental e Ensino Médio, sendo 36 estaduais, 53 municipais e 21 privadas (RIO GRANDE DO SUL, 2010). Das 110 escolas, 104 (94,5\%) aceitaram participar da pesquisa, sendo que apenas seis $(28,6 \%)$ escolas particulares não aceitaram participar.

Para avaliação do comércio de alimentos nas escolas, foi elaborado um instrumento, o qual foi previamente testado em um estudo-piloto. $\mathrm{O}$ instrumento continha três seções: 1) informações gerais da escola (localização, nível e âmbito de ensino, gestor); 2) informações sobre o comércio informal (sujeitos envolvidos nesse tipo de comércio, quais alimentos comercializados, partindo-se de uma listagem prévia de 32 alimentos comumente vendidos em escolas); 3) informações referentes ao comércio formal (tipo de administração da cantina, quais alimentos comercializados, conforme já descrito na seção anterior, quais alimentos mais vendidos, conhecimento e conteúdo da legislação das cantinas escolares do Estado do Rio Grande do Sul (Lei 13.027/2008) pelos gestores das escolas e cantineiros, avaliação de adequação das cantinas perante itens da lei das cantinas, por meio de um check-list elaborado).

Inicialmente, realizou-se contato por telefone com as escolas, a fim de averiguar o tipo de comércio de alimentos adotado pela instituição. Foi realizada entrevista por telefone com o gestor da escola, quando havia apenas comércio informal de alimentos, contemplando as seções 1 e 2 do instrumento. Ocorreu visita in loco, quando existia cantina na escola. Durante a visita, os gestores das escolas e os responsáveis pelas cantinas foram entrevistados, contemplando as seções 1 e 3 do instrumento. Quando autorizado, foi realizado um registro fotográfico da apresentação dos alimentos na cantina. 
A pesquisa foi aprovada pelo Comitê de Ética em Pesquisa com Seres Humanos do Centro Universitário Franciscano, registro na CONEP 12.456, registro CEP/UNIFRA 054.2011.2.

Frequências absolutas e relativas foram utilizadas para descrever as variáveis quantitativas e, para avaliar as diferenças entre as variáveis categóricas, o teste qui-quadrado foi aplicado. O nível de significância adotado foi de $5 \%(p<0,05)$ e as análises foram realizadas no programa SPSS (Statistical Package for the Social Sciences) versão 18.0.

\section{Resultados e Discussões}

Das 110 escolas, 104 (94,5\%) aceitaram participar da pesquisa, sendo 53 municipais, 36 estaduais e 15 particulares. No presente estudo, obteve-se um percentual de perdas e recusas de $5,5 \%$, sendo referentes a seis escolas da rede particular de ensino. A maioria das escolas $(87,5 \%)$ está localizada na área urbana do município.

Existe comércio de alimentos em 72 (69,2\%) das 104 escolas avaliadas, destacando que o comércio informal de alimentos ocorre em $42(40,4 \%)$ e o formal, em 30 escolas $(28,8 \%)$. Os dados apontam que existe uma diferença estatística significativa entre os âmbitos de ensino, havendo maior prevalência de comércio informal nas escolas da rede municipal e maior prevalência de comércio formal nas escolas particulares (Tabela 1).

O comércio informal de alimentos nas escolas é efetivado por meio de diferentes atores, como ambulantes externos, alunos, professores e armário da escola, sendo que estes dois últimos são realizados apenas em escolas municipais, verificando-se diferença estatística significativa entre os âmbitos (Tabela 2).

Salienta-se que uma das modalidades desse tipo de comércio, que se denominou como "armário da escola", compreende um móvel localizado na sala da Secretaria ou da Direção da escola, no qual estavam armazenados alimentos, como balas, pirulitos, salgadinhos industrializados e bolachas recheadas. Esse comércio era de responsabilidade do Diretor ou de outro professor designado, que possuía a responsabilidade da venda desses produtos. Esse resultado é alarmante, na medida em que, além de serem alimentos de baixa qualidade nutricional, há uma incoerência no que se refere a todo o contexto escolar, pois os próprios educadores que prezam por uma alimentação saudável, na teoria, em sala de aula, são os mesmos que estão dispondo alimentos inadequados aos alunos.

Gabriel et al. (2010) observaram que, das 105 escolas participantes do estudo, realizado em Florianópolis-SC, 26,7\% possuíam venda informal de alimentos. Já Sá (2009) relataram que $10 \%$ das escolas públicas investigadas possuíam venda de ambulantes e todas as escolas particulares não possuíam este comércio, diferentemente do presente estudo, em que se notou venda informal em todos os âmbitos. De acordo com os relatos dos gestores das escolas, salgados fritos e bolo de chocolate são os alimentos ofertados com maior frequência na venda informal de alimentos, mas o item que apresenta diferença estatística significativa, entre os âmbitos, são as balas, conforme a Tabela 3. Sugere-se que essa significância estatística tenha se dado pela existência do comércio de balas por meio do "armário da escola", realizado somente nas escolas da rede municipal de ensino.

Apesar de a lei em questão não referir sobre a venda informal de alimentos no ambiente escolar, esse fato merece atenção, pois, para Willhelm et al. (2010), os produtos comercializados desta forma tendem a ser ricos em gorduras e açúcares. Os autores chegaram a esta conclusão a partir de um estudo que avaliou 26 cantinas

Tabela 1. Comércio de alimentos nas escolas dos âmbitos municipal, estadual e particular, de um município do Rio Grande do Sul, 2011

\begin{tabular}{lcccr}
\multicolumn{1}{c}{ Comércio } & Municipal $(\mathbf{n = 5 3})$ & Estadual $(\mathbf{n = 3 6 )}$ & Particular $(\mathbf{n = 1 5})$ & $\boldsymbol{p}^{*}$ \\
Informal & $26(49,1)$ & $14(38,9)$ & $2(13,3)$ & $0,04^{*}$ \\
Formal (Cantina) & $9(17,0)$ & $10(27,8)$ & $11(73,4)$ & $<0,001^{*}$ \\
Ausência de comércio & $18(33,9)$ & $12(33,3)$ & $2(13,3)$ & \\
\hline
\end{tabular}

*Teste qui-quadrado de Pearson $(p<0,05)$.

Tabela 2. Atores do comércio informal de alimentos nas escolas dos âmbitos municipal, estadual e particular, de um município do Rio Grande do Sul, 2011

\begin{tabular}{|c|c|c|c|c|c|}
\hline $\begin{array}{l}\text { Atores do comércio informal de } \\
\text { alimentos }\end{array}$ & Municipal $(n=26)$ & Estadual $(n=14)$ & Particular $(n=2)$ & Total $(n=42)$ & $p^{\star}$ \\
\hline Ambulantes externos & $5(19,2)$ & $5(35,7)$ & $0(0,0)$ & $10(23,8)$ & 0,09 \\
\hline Alunos & $13(50,0)$ & $9(64,3)$ & $2(100)$ & $24(57,1)$ & 0,31 \\
\hline Professores & $8(30,8)$ & $0(0,0)$ & $0(0,0)$ & $8(19,0)$ & $0,04^{*}$ \\
\hline Armário da escola & $9(34,6)$ & $0(0,0)$ & $0(0,0)$ & $9(21,4)$ & $0,02^{*}$ \\
\hline
\end{tabular}

Valores apresentados em $\mathrm{n}(\%)$; ${ }^{*}$ Teste qui-quadrado de Pearson $(p<0,05)$; Na venda informal, considerou-se mais de uma opção. 
escolares da rede pública estadual da cidade de Porto Alegre-RS, o que se pôde confirmar com o presente estudo, visto que as escolas estão disponibilizando alimentos inadequados por meio desse tipo de comércio (Tabela 3). Além disso, é de extrema importância a verificação das condições higiênico-sanitárias desta forma comercial, já que, para Danelon e Silva (2007), algumas situações revelam riscos para a saúde dos alunos ao adquirirem alimentos vendidos no comércio informal.

Em relação ao comércio formal de alimentos no âmbito escolar, salienta-se que $30(28,8 \%)$ escolas pesquisadas possuíam cantina (Tabela 1), sendo que, durante o estudo, houve duas $(6,6 \%)$ perdas. Portanto, o formulário foi aplicado com oito donos de cantinas das escolas municipais, nove das estaduais e 11 das particulares, totalizando $28(26,8 \%)$ cantinas avaliadas das escolas pesquisadas.
No presente estudo, a presença de cantina é mais prevalente nas escolas particulares (Tabela 1), o que vem ao encontro do estudo de Gabriel et al. (2010), que observaram $88,6 \%$ de presença de cantina em escolas particulares. Percebeu-se ainda que, na grande maioria (82,1\%), a administração do estabelecimento era do tipo terceirizada, condizendo com os achados de Gabriel et al. (2010), em cantinas escolares de Florianópolis-SC, e de Willhelm et al. (2010), em cantinas escolares de Porto Alegre-RS.

A Tabela 4 apresenta a relação dos alimentos e bebidas ofertados nas cantinas das escolas. Em relação aos salgados, houve maior oferta de salgados fritos e folhados. Nas escolas municipais, os sanduíches são menos ofertados; já os salgadinhos industrializados, tanto nas escolas municipais quanto nas estaduais, são os mais ofertados, quando comparados aos das cantinas particulares,

Tabela 3. Alimentos e bebidas ofertados no comércio informal de alimentos nas escolas de um município do Rio Grande do Sul, 2011.

\begin{tabular}{lrcccc}
\multicolumn{1}{c}{ Alimentos } & Municipal $(\mathbf{n = 2 6 )}$ & Estadual $(\mathbf{n = 1 4 )}$ & Particular $(\mathbf{n = 2})$ & Total $(\mathbf{n}=\mathbf{4 2})$ & $\boldsymbol{p}^{*}$ \\
Salgados fritos & $13(50,0)$ & $10(71,4)$ & $1(50,0)$ & $24(57,1)$ & 0,71 \\
Cachorro-quente & $9(34,6)$ & $3(21,4)$ & $0(0,0)$ & $12(28,6)$ & 0,67 \\
Bolo de chocolate & $12(46,2)$ & $10(71,4)$ & $1(50,0)$ & $23(54,8)$ & 0,48 \\
Bolos em geral & $7(26,9)$ & $4(28,6)$ & $1(50,0)$ & $12(28,6)$ & 0,66 \\
Balas em geral & $12(46,2)$ & $1(7,1)$ & $0(0,0)$ & $13(31,0)$ & $0,02^{\star}$ \\
Refrigerante & $12(46,2)$ & $5(35,7)$ & $1(50,0)$ & $18(42,9)$ & 0,68 \\
\hline
\end{tabular}

Valores apresentados em $\mathrm{n}(\%) ;{ }^{*}$ Teste qui-quadrado de Pearson $(p<0,05)$.

Tabela 4. Alimentos e bebidas ofertadas nas cantinas escolares dos âmbitos municipal, estadual e privado, de um município do Rio Grande do Sul, 2011

\begin{tabular}{lccccc}
\multicolumn{1}{c}{ Alimentos e bebidas } & Municipal (n=8) & Estadual (n=9) & Particular $(\mathbf{n = 1 1})$ & Total (n=28) & $\boldsymbol{p}^{*}$ \\
Salgados fritos e folhados & $7(87,5)$ & $9(100)$ & $11(100)$ & $27(96,4)$ & 0,27 \\
Salgados assados e pão de queijo & $5(62,5)$ & $9(100)$ & $11(100)$ & $25(89,3)$ & $0,01^{*}$ \\
Torradas e sanduíches & $6(75,0)$ & $8(88,9)$ & $11(100)$ & $25(89,3)$ & 0,22 \\
Bolachas salgadas & $5(62,5)$ & $8(88,9)$ & $8(72,7)$ & $21(75,0)$ & 0,44 \\
Cachorro-quente, pizza, hambúrguer & $7(87,5)$ & $8(88,9)$ & $11(100)$ & $26(92,9)$ & 0,49 \\
Salgadinhos industrializados & $6(75,0)$ & $7(77,8)$ & $6(54,5)$ & $19(67,8)$ & 0,47 \\
Bolachas recheadas & $7(87,5)$ & $7(77,8)$ & $8(72,7)$ & $22(78,6)$ & 0,73 \\
Barras de cereal & $5(62,5)$ & $8(88,9)$ & $9(81,8)$ & $22(78,6)$ & 0,39 \\
Salada de frutas ou frutas frescas & $4(50,0)$ & $2(22,2)$ & $11(100)$ & $17(60,7)$ & $0,01^{*}$ \\
Chocolate e brigadeiro & $6(75,0)$ & $8(88,9)$ & $9(81,8)$ & $23(82,1)$ & 0,75 \\
Balas, gomas, chicletes, pirulitos & $8(100)$ & $9(100)$ & $10(90,9)$ & $27(96,4)$ & 0,44 \\
Picolés, sorvetes & $3(37,5)$ & $4(44,4)$ & $7(63,6)$ & $14(50,0)$ & 0,48 \\
Gelatina & $3(37,5)$ & $0(0,0)$ & $5(45,5)$ & $8(28,6)$ & 0,06 \\
Bolos em geral & $5(62,5)$ & $6(66,7)$ & $8(72,7)$ & $19(67,9)$ & 0,89 \\
Suco de frutas natural & $4(50,0)$ & $5(55,6)$ & $9(81,8)$ & $18(64,3)$ \\
Suco de frutas industrializado & $5(62,5)$ & $8(88,9)$ & $11(100)$ & $24(85,7)$ & 0,28 \\
Refrigerantes & $8(100)$ & $9(100)$ & $10(90,9)$ & $27(96,4)$ & 0,06 \\
Água & $7(87,5)$ & $9(100)$ & $11(100)$ & $27(96,4)$ & 0,44 \\
Chá e café & $1(12,5)$ & $8(88,9)$ & $8(72,7)$ & $17(60,3)$ & 0,27 \\
logurte & $0(0,0)$ & $0(0,0)$ & $6(54,5)$ & $6(21,4)$ & $0,03^{*}$ \\
Achocolatados e chocolate quente & $5(62,5)$ & $7(77,8)$ & $9(81,8)$ & $21(75,0)$ & 0,61 \\
\hline Valos & & &
\end{tabular}

Valores apresentados em $n(\%) ;{ }^{*}$ Teste qui-quadrado de Pearson $(p<0,05)$. 
sem, contudo, diferença estatística. Observou-se que os únicos alimentos salgados que apresentam diferença significativa entre os setores educacionais são os assados e o pão de queijo, sendo menos ofertados nas cantinas do âmbito municipal.

Em relação aos doces (Tabela 4), percebeu-se que balas em geral, gomas, pirulitos, chicletes, chocolates e brigadeiros são oferecidos na grande maioria das cantinas. Salientam-se as cantinas municipais, as quais oferecem mais bolachas recheadas e menos salada de fruta e frutas frescas, quando comparadas às outras cantinas. Já as cantinas particulares oferecem saladas de frutas ou frutas secas na sua totalidade, havendo diferença estatística entre os âmbitos.

Quanto às bebidas (Tabela 4), nota-se que os refrigerantes, os sucos industrializados e a água são as bebidas ofertadas na maioria das cantinas. Ressalta-se que os sucos naturais são mais ofertados nas cantinas particulares e os iogurtes, somente nas particulares. Dados semelhantes foram encontrados por Gabriel et al. (2009), em relação às bebidas, em que as cantinas das escolas privadas se distinguiram das escolas públicas por meio da oferta de água mineral, água de coco, bebidas de soja, iogurte, leite e/ou vitaminas, suco de fruta e de polpa. Destaca-se também a diferença de oferta de bebidas nos tipos de comércio de alimentos do presente estudo. Preocupantemente, refrigerante é única bebida ofertada no comércio informal (Tabela 3), propiciando ao aluno somente a opção não saudável.

Em dois estudos realizados no Estado de Santa Catarina, a maioria das cantinas (68,2\% e 64,7\%, respectivamente) não ofertava salgados fritos, refrigerantes, industrializados, pipocas, balas, pirulitos, gomas de mascar e salgadinhos industrializados (GABRIEL et al., 2009; DANELON; SILVA, 2007), diferentemente dos resultados do presente estudo. Tal fato pode ser explicado pelo fato de a Lei 13.029/2008 do Estado do Rio Grande do Sul não definir alimentos proibidos para a venda; já a Lei 12.061/2001 de Santa Catarina proíbe a comercialização de produtos de baixo valor nutricional (RIO GRANDE DO SUL, 2008; SANTA
CATARINA, 2001). Outros municípios também proíbem alguns desses alimentos, amparados pela legislação de Belo Horizonte (2003), Natal (2006), Ribeirão Preto (2002) e Rio de Janeiro (2002).

Segundo o Art. $1^{\circ}$ da Lei 13.029/2008, o comércio de lanches e de bebidas realizado nas escolas deve atender essencialmente ao perfil de produtos e de serviços que visem à saúde e à qualificação nutricional dos alunos (RIO GRANDE DO SUL, 2008), o que se pôde perceber que não está ocorrendo na maioria das escolas do município estudado. Enfatiza-se que as escolas particulares possuem as cantinas como a principal forma de abastecimento de alimentos e que estes possuem alto valor energético. Com isso, menciona-se o estudo de Araújo et al. (2010), em que as prevalências mais elevadas de excesso de peso e obesidade encontram-se entre os adolescentes das escolas privadas.

Referenciando-se a gravidade do problema, a Pesquisa Nacional da Saúde do Escolar (PeNSE) apontou que, na média das capitais brasileiras, as maiores prevalências de escolares com sobrepeso foram observadas entre os alunos das escolas privadas, ao exemplo de Porto Alegre-RS, que apresentou 18,9\% de escolares com sobrepeso em escolas públicas e $23,4 \%$, em escolas privadas. Ao passo que as maiores frequências de obesidade de escolares do 9. ${ }^{\circ}$ ano do Ensino Fundamental, segundo os dados dos municípios das capitais e o Distrito Federal, tanto em escolares da rede pública quanto particular, foram observadas em Porto Alegre-RS (10,5\%) (BRASIL, 2010b).

Em relação aos alimentos mais vendidos nas cantinas escolares (Tabela 5), constatou-se que, nas cantinas municipais, são os salgados fritos e folhados; nas estaduais, são os cachorros-quentes, pizzas e hambúrgueres; já nas privadas, são os salgados assados. Dentre os alimentos doces e as bebidas, os mais vendidos são as balas em geral, as gomas e os pirulitos nas cantinas das escolas municipais e estaduais; nas cantinas das escolas particulares, são os chocolates; já em relação às bebidas, são os refrigerantes, em todos os âmbitos. Dessa forma, corrobora-se com estudos anteriores, os

Tabela 5. Alimentos e bebidas vendidos com maior frequência nas cantinas escolares dos âmbitos municipal, estadual e privado, de um município do Rio Grande do Sul, 2011.

\begin{tabular}{|c|c|c|c|c|c|}
\hline Alimentos & Municipal $(n=8)$ & Estadual $(n=9)$ & Privada $(n=11)$ & Total $(n=28)$ & $\boldsymbol{p}^{*}$ \\
\hline \multicolumn{6}{|l|}{ Salgados } \\
\hline Cachorro-quente, pizza, hambúrguer & $3(37,5)$ & $6(66,7)$ & $6(54,5)$ & $15(53,6)$ & 0,48 \\
\hline Salgados assados, pão de queijo & $1(12,5)$ & $4(44,4)$ & $7(63,7)$ & $12(42,9)$ & 0,15 \\
\hline Salgados fritos, folhados & $4(50,0)$ & $4(44,4)$ & $3(27,3)$ & $11(39,3)$ & 0,37 \\
\hline \multicolumn{6}{|l|}{ Doces } \\
\hline Balas, gomas, chicletes, pirulitos & $5(62,5)$ & $8(88,9)$ & $5(45,5)$ & $18(64,3)$ & 0,33 \\
\hline Chocolate, brigadeiro & $3(37,5)$ & $6(66,7)$ & $7(63,7)$ & $16(57,1)$ & 0,64 \\
\hline \multicolumn{6}{|l|}{ Bebidas } \\
\hline Refrigerante & $6(75,0)$ & $9(100)$ & $7(63,6)$ & $22(78,6)$ & 0,13 \\
\hline
\end{tabular}

Valores apresentados em $\mathrm{n}(\%)$; ${ }^{\star}$ Teste qui-quadrado de Pearson $(p<0,05)$. 
quais demonstram que os alimentos preferidos comprados em cantinas escolares, por crianças e adolescentes, são salgados, refrigerantes e balas, ricos em energia, açúcares, gordura e sal (SÁ, 2009; ZANCUL; DAL FABRO, 2007; STURION et al., 2005).

Neste sentido, um estudo com escolas da rede pública observou que alimentos, como biscoitos, doces, guloseimas e salgados caseiros, eram os preferidos dos escolares, apesar de 56,1\% dos mesmos avaliarem esses alimentos como não sendo os melhores para a saúde do que aqueles oferecidos pela alimentação escolar (RODRIGUES et al., 2011). A percepção dos alunos acerca da alimentação ofertada pela escola é fundamental na construção de um ambiente escolar saudável, fato este reforçado pelo estudo de Albuquerque et al. (2014), no qual os autores puderam observar que, para as crianças de uma escola pública, o ambiente escolar não tem proporcionado escolhas saudáveis. Somado a isso, é necessário uma efetiva educação alimentar e nutricional, a fim de que uma mudança de hábitos alimentares saudáveis ocorra permanentemente.

Evidencia-se, na Tabela 6, através da avaliação da Lei n. ${ }^{\circ}$ 13.027/2008, que somente 14 (50\%) das cantinas escolares avaliadas ofertam alimentos saudáveis, tais como frutas, saladas, sucos naturais ou sanduíches. Das cantinas particulares que ofertam alimentos, somente três $(27,3 \%)$ expõem esses alimentos de forma mais evidente, estando as demais em desacordo com o Art. 2. ${ }^{\circ}$ da referida Lei (RIO GRANDE DO SUL, 2008). Apesar de 11 (39,3\%) das cantinas referirem possuir alvará sanitário, apenas em quatro $(14,3 \%)$ dos estabelecimentos, os alvarás estão em locais visíveis; além disso, apenas em uma $(9,1 \%)$ escola privada, a cantina apresenta painel visível sobre alimentação saudável, fatos estes que contrariam o disposto nessa Lei (Art. $4^{\circ}{ }^{\circ}$.
Em contrapartida, 25 (92,3\%) das escolas não possuem publicidade de balas, chicletes, salgadinhos industrializados e refrigerantes, sendo este um ponto positivo, conforme o Art. 5. (RIO GRANDE DO SUL, 2008). No estudo de Willhelm et al. (2010), também foi verificada a ausência de publicidade destes alimentos em 93\% das escolas estaduais avaliadas. Porém, somente $10,7 \%$ das cantinas não expõem ostensivamente estes alimentos. Nesta perspectiva, a lei refere proibição de publicidade somente de balas, chicletes, salgadinhos industrializados e refrigerantes (RIO GRANDE DO SUL, 2008). Porém, algumas escolas possuem cartazes de bolachas recheadas, sorvetes e sucos industrializados, ou seja, publicidade de alimentos igualmente não saudáveis, sendo este um ponto a ser revisto na legislação.

Em um estudo, French (2003) avaliou o efeito dos preços nas escolhas de alimentos de escolares adolescentes norte-americanos e verificou que uma diminuição dos preços das frutas comercializadas aumentou o seu consumo, no ambiente escolar. Estudo semelhante realizado na Austrália constatou que, em cantinas com oferta de uma maior variedade de alimentos, promoções e marketing obtiveram estratégias bem sucedidas nas vendas de frutas e saladas (DRUMMOND; SHEPPARD, 2004).

Além disso, os conhecimentos recebidos na escola poderão ser esquecidos ou ignorados, se os alimentos comercializados no ambiente escolar não estiverem em concordância com os princípios de uma alimentação saudável (DANELON et al., 2006). Ainda, esforço individual e iniciativas governamentais são necessários para melhorar a alimentação nesse ambiente (MUNIZ et al., 2013).

Adicionado a isso, desde 2010, o Ministério da Saúde lançou o Manual das Cantinas Escolares Saudáveis - Promovendo a Alimentação Saudável (BRASIL, 2010b),

Tabela 6. Avaliação dos itens da Lei n. ${ }^{\circ}$ 13.027/2008 nas cantinas escolares dos âmbitos municipal, estadual e privado, de um município do Rio Grande do Sul, 2011.

\begin{tabular}{|c|c|c|c|c|c|}
\hline Itens da Lei & Municipal $(n=8)$ & Estadual $(n=9)$ & Privada $(n=11)$ & Total $(n=28)$ & $p^{*}$ \\
\hline $\begin{array}{l}\text { Oferta de frutas, saladas, sucos naturais } \\
\text { e sanduíches }\end{array}$ & $1(12,5)$ & $4(44,3)$ & $9(81,8)$ & $14(50,0)$ & $0,03^{*}$ \\
\hline $\begin{array}{l}\text { Oferta mais evidente de frutas, saladas, } \\
\text { sucos naturais e sanduíches }\end{array}$ & $0(0,0)$ & $(0,0)$ & $3(27,3)$ & $3(10,7)$ & 0,05 \\
\hline $\begin{array}{l}\text { Painel informativo visível tratando de } \\
\text { alimentação saudável }\end{array}$ & $0(0,0)$ & $0(0,0)$ & $1(9,1)$ & $1(3,6)$ & 0,44 \\
\hline $\begin{array}{l}\text { Ausência de cartazes publicitários } \\
\text { de balas, chicletes, salgadinhos } \\
\text { industrializados e refrigerantes }\end{array}$ & $8(100)$ & $7(77,8)$ & $10(90,9)$ & $25(92,3)$ & 0,32 \\
\hline $\begin{array}{l}\text { Ausência de exposição ostensiva } \\
\text { de balas, chicletes, salgadinhos } \\
\text { industrializados e refrigerantes }\end{array}$ & $0(0,0)$ & $0(0,0)$ & $3(27,3)$ & $3(10,7)$ & 0,10 \\
\hline Presença de alvará sanitário & $1(12,5)$ & $3(33,3)$ & $7(63,6)$ & $11(39,3)$ & 0,05 \\
\hline Alvará sanitário em local visível & $0(0,0)$ & $0(0,0)$ & $4(36,4)$ & $4(14,3)$ & 0,06 \\
\hline
\end{tabular}

Valores apresentados em $n(\%)$; ${ }^{*}$ Teste qui-quadrado de Pearson $(p<0,05)$. 
com a intenção de auxiliar os donos destes estabelecimentos a implantar a cantina escolar saudável. Tal manual evidencia o dono da cantina como uma peça-chave para a construção coletiva de ações de promoção da saúde. Para Gabriel et al. (2012), além de legislações específicas, é necessário acompanhamento do processo de implantação e envolvimento da comunidade escolar para a efetiva implantação e manutenção da cantina escolar saudável.

Em relação ao conhecimento da lei das cantinas, metade dos gestores das escolas relatou ter algum conhecimento, porém, após avaliação da pergunta aberta sobre do que se trata a lei, percebeu-se que somente um $(6,7 \%)$ gestor a conhecia profundamente, sendo este de escola particular. Quanto ao conhecimento por parte dos cantineiros, verificou-se que quase metade $(n=13,46,4 \%)$ referiu conhecer a lei e, destes, $10(35,7 \%)$ possuíam algum conhecimento, porém muito superficial, nenhum tinha conhecimento completo da mesma (resultados não apresentados em tabela). Esses resultados são preocupantes, pois se percebe a falta de informação dos atores envolvidos com a cantina escolar em relação à legislação vigente, sendo necessárias capacitações efetivas para esse público. Resultados diferentes foram encontrados por Metzner (2010), os quais verificaram que $100 \%$ e $50 \%$ dos cantineiros de escolas particulares e municipais, respectivamente, apresentavam conhecimento da lei no município de Blumenau-SC

Os resultados do presente estudo indicam que as cantinas escolares do município estão atrasadas no que se refere à promoção de práticas alimentares saudáveis, no ambiente escolar, bem como na implementação da legislação das cantinas vigente no Estado do Rio Grande do Sul, em relação aos estudos de cantinas escolares de outros municípios e Estados do Brasil (GABRIEL et al., 2009, 2010; ARCAN et al., 2011), o que sugere que intervenções são necessárias. Arcan et al. (2011) afirmam que as mediações da escola devem se concentrar em mudar o cenário de oportunidades de alimentos, como alternativas para aumentar a disponibilidade de alimentos e bebidas saudáveis.

Apesar de a lei avaliada não proibir os alimentos comercializados nas cantinas escolares, a mesma é de valia, pois serve de estratégia para melhorar a alimentação oferecida nas cantinas, bem como é um subsídio para as escolas desenvolverem educação nutricional. Salienta-se que orientações sobre a lei são necessárias, tanto para os gestores das escolas como para os responsáveis pelas cantinas; após tais orientações, é preciso fiscalização, em conjunto com ações educativas, para proporcionar alimentos saudáveis e promover educação nutricional nas escolas.

Tendo em vista que o nutricionista é o profissional que possui a atribuição de realizar o planejamento, a organização, a supervisão e a avaliação das unidades de alimentação e nutrição escolares, assim como é responsável por prestar assistência e educação nutricional aos indivíduos envolvidos (CFN, 2006), destaca-se o seu papel fundamental como promotor de saúde, tanto nas escolas da rede pública quanto da rede privada.

Com base nestes resultados, pode-se constatar que o PNAE possui papel importante no ambiente das escolas públicas. Este fato deve-se a todo o embasamento legal construído, assim como pelas suas características e políticas metodológicas. Dessa maneira, o comércio de alimentos nas instituições de ensino deve se adequar ao cenário epidemiológico nacional de aumento da obesidade infantil ou sugere-se, ainda, proibir este tipo de estabelecimento em escolas públicas, em virtude da existência do PNAE. Esta situação também cabe às escolas particulares, pois a educação alimentar e nutricional preconizada na sala de aula deve ser vivenciada fora dela.

\section{Conclusões}

Após analisar o comércio informal e formal de alimentos nas escolas do município estudado, bem como avaliar a vigência da lei estadual da regulamentação das cantinas escolares, pode-se concluir que:

- Existe comércio de alimentos na maioria das escolas;

- A maior prevalência de comércio informal de alimentos ocorre nas escolas da rede municipal de ensino. Nesse tipo de comércio, estão disponibilizando alimentos de baixo valor nutricional e ricos em energia, açúcares, gordura e sal;

- A presença de comércio formal é mais prevalente nas escolas privadas, sendo que a administração da maioria das cantinas é terceirizada;

- Alimentos de baixo valor nutricional são oferecidos na maioria das cantinas, observando-se, também, que são estes alimentos os mais vendidos nesse tipo de comércio;

- Os gestores das escolas e os responsáveis pelas cantinas, na sua maioria, não conhecem a Lei 13.027/2008 do Rio Grande do Sul, sendo necessárias capacitações;

- Nenhuma cantina escolar está cumprindo a lei na sua totalidade; porém, as cantinas das escolas particulares apresentam resultados mais satisfatórios quando comparadas às cantinas dos outros âmbitos;

- Estes resultados podem auxiliar para a elaboração de estratégias para realizar educação nutricional nas escolas; também podem servir para a elaboração e a implementação de políticas públicas, o que poderá refletir na alimentação dos escolares. 


\section{Referências}

ALBUQUERQUE, O. M. R.; MARTINS, A. M.; MODENA, C. M.; CAMPOS, H. M. Percepção de estudantes de escolas públicas sobre o ambiente e a alimentação disponível na escola: uma abordagem emancipatória. Saúde e Sociedade, v. 23, n. 2, p. 604-615, 2014. http://dx.doi.org/10.1590/S0104-12902014000200020.

ARAÚJO, C.; TORAL, N.; SILVA, A. C. F.; VELÁSQUEZ-MELENDEZ, G.; DIAS, A. J. R. Estado nutricional dos adolescentes e sua relação com variáveis sociodemográficas: Pesquisa Nacional de Saúde do Escolar (PeNSE), 2009. Ciência \& Saúde Coletiva, v. 15, n. 2, p. 3077-3084, 2010. Suplemento 2. PMid:21049148. http://dx.doi.org/10.1590/S1413-81232010000800012.

ARCAN, C.; KUBIK, M. Y.; FULKERSON, J. A.; DAVEY, C.; STORY, $M$. Association between food opportunities during the school day and selected dietary behaviors of alternative high school students, Minneapolis/Saint Paul, Minnesota, 2006. Preventing Chronic Disease, v. 8, n. 1, p. A08, 2011. PMid:21159220.

BELO HORIZONTE. Lei n 8.650, 25 de setembro de 2003. Dispõe sobre a proibição, em escola da rede pública municipal de ensino, de adquirir, confeccionar, distribuir e comercializar os produtos que menciona e dá outras providências. Diário Oficial do Município, Belo Horizonte, 26 set, 2003.

BRASIL. Ministério da Saúde; Ministério da Educação. Portaria interministerial $n^{\circ} 1010$, de 8 de maio de 2006. Institui as diretrizes para a promoção da alimentação saudável nas escolas de educação infantil, fundamental e nível médio das redes públicas e privadas, em âmbito nacional. Diário Oficial [da] República Federativa do Brasil, Brasília, DF, 9 maio 2006. Seção 1.

BRASIL. Ministério da Saúde. Secretaria de Atenção a Saúde. Departamento de Atenção Básica. Manual das cantinas escolares saudáveis: promovendo alimentação saudável. Brasília: Editora do Ministério da Saúde, 2010a.

BRASIL. Ministério do Planejamento, Orçamento e Gestão. Instituto Brasileiro de Geografia e Estatística - IBGE. Pesquisa Nacional de Saúde do Escolar (PeNSE): avaliação do Estado Nutricional dos Escolares do $9^{\circ}$ Ano do Ensino Fundamental Municípios das Capitais e Distrito Federal. Rio de Janeiro: IBGE, 2010b.

CONSELHO FEDERAL DE NUTRICIONISTAS - CFN. Resolução CFN n 380 de 28 de dezembro de 2005. Dispõe sobre a definição das áreas de atuação do nutricionista e suas atribuições, estabelece parâmetros numéricos de referência, por área de atuação, e dá outras providências. Diário Oficial [da] República Federativa do Brasil, Brasília, DF, 10 jan 2006.

DANELON, M. A. S.; DANELON, M. S.; SILVA, M. V. Serviços de alimentação destinados ao público escolar: análise da convivência do Programa de Alimentação Escolar e das cantinas. Revista Segurança Alimentar e Nutricional, v. 13, n. 1, p. 85-94, 2006.

DANELON, M. S.; SILVA, M. V. Análise das condições higiênicosanitárias das áreas de preparo e consumo de alimentos, disponíveis para alunos de escolas públicas e privadas. Higiene Alimentar, v. 23, n. 152, p. 25-30, 2007.

DRUMMOND, C.; SHEPPARD, L. South Australian school canteens 2003: Revisiting the 1990 school canteen/tuckshop survey. Jounal of the HEIA, v. 11, n. 3, p. 13-22, 2004.

FLORIANÓPOLIS. Lei n 5853, de 4 de junho de 2001. Dispõe sobre os critérios de concessão de serviços de lanches e bebidas, nas unidades educacionais, localizadas no município de Florianópolis. Diário Oficial do Município, Florianópolis, SC, 5 jun. 2001.

FRENCH, S. A. Pricing effects on food choices. The Journal of Nutrition, v. 133, n. 3, p. 841S-843S, 2003. PMid:12612165.

GABRIEL, C. G.; VASCONCELOS, F. A.; ANDRADE, D. F.; SCHMITZ, B. A. First law regulating school canteens in Brazil: evaluation after seven years of implementation. Archivos Latinoamericanos de Nutricion, v. 59, n. 2, p. 128-138, 2009. PMid:19719008.

GABRIEL, C. G.; SANTOS, M. V.; VASCONCELOS, F. A. G.; MILANEZ, G. H. G.; HULSE, S. B. Cantinas escolares de Florianópolis: existência e produtos comercializados após a instituição da Lei de Regulamentação. Revista de Nutrição, v. 23, n. 2, p. 191-199, 2010. http://dx.doi.org/10.1590/S141552732010000200002.

GABRIEL, C. G.; RICARDO, G. D.; OSTERMANN, R. M.; CORSO, A. C. T.; DE ASSIS, M. A. A.; DI PIETRO, P. F.; DE VASCONCELOS, F. A. G. Regulamentação da comercialização de alimentos no ambiente escolar: análise dos dispositivos legais brasileiros que buscam a alimentação saudável. Revista do Instituto Adolfo Lutz, v. 71, n. 1, p. 11-20, 2012.

METZNER, A. K. P. Cumprimento da lei das cantinas e sua comparação entre escolas da rede pública e privada no município de Blumenau - SC. In: SIMPÓSIO DE SEGURANÇA ALIMENTAR, 3., 2010, Florianópolis. Anais... Florianópolis: UFRGS, 2010.

MUNIZ, L. D.; ZANINI, R. V.; SCHNEIDER, B. C.; TASSITANO, R. M.; FEITOSA, W. M. N.; GONZÁLEZ-CHICA, D. A. Prevalência e fatores associados ao consumo de frutas, legumes e verduras entre adolescentes de escolas públicas de Caruaru, PE. Ciência \& Saúde Coletiva, v. 18, n. 2, p. 393-404, 2013. PMid:23358765. http://dx.doi.org/10.1590/S1413-81232013000200011.

NATAL. Lei $n^{\circ}$ 0245, de 16 de agosto de 2006. Dispõe sobre padrões técnicos de qualidade nutricional, a serem seguidos pelas lanchonetes e similares, instaladas nas escolas de ensino fundamental e médio, particulares e da rede pública e dá outras providências. Diário Oficial do Município, Natal, RN, 17 ago. 2006.

PARANÁ. Lei nº 14.423 de 02 de junho de 2004. Dispõe que os serviços de lanches nas unidades educacionais públicas e privadas que atendam a educação básica, localizadas no Estado, deverão obedecer a padrões de qualidade nutricional e de vida, indispensáveis à saúde dos alunos. Diário Oficial Paraná, Parará, PR, 3 jun. 2004. 
PARANÁ. Lei nº 14.855 de 19 de outubro de 2005. Dispõe sobre padrões técnicos de qualidade nutricional, a serem seguidos pelas lanchonetes e similares, instaladas nas escolas de ensino fundamental e médio, particulares e da rede pública. Diário Oficial Paraná, Parará, PR, 20 out. 2005.

PORTO ALEGRE. Lei n 10.167, de 24 de janeiro de 2007. Estabelece, no Município de Porto Alegre, normas para o controle da comercialização de produtos alimentícios e de bebidas nos bares e nas cantinas das escolas públicas e privadas e dá outras providências. Diário Oficial de Porto Alegre, Porto Alegre, RS, 26 jan. 2007

RIBEIRÃO PRETO. Resolução n 16, de 29 de julho de 2002. Diário Oficial do Município de Ribeirão Preto, Ribeirão Preto, SP, 2 ago. 2002.

RIO DE JANEIRO. Decreto n² 21.217 de 1 de abril de 2002. Proíbe no âmbito das unidades escolares da rede municipal de ensino adquirir, confeccionar, distribuir e consumir os produtos que menciona. Diário Oficial do Município, Rio de Janeiro, RJ, 2 abr. 2002.

RIO DE JANEIRO. Lei n 4.508 de 11 de janeiro de 2005. Proíbe a comercialização, aquisição, confecção e distribuição de produtos que colaborem para a obesidade infantil, em bares, cantinas e similares instalados em escolas públicas e privadas do Estado do Rio de Janeiro, na forma que menciona. Diário Oficial do Estado, Rio de Janeiro, RJ, 2005

RIO GRANDE DO SUL. Lei n 13.027, de 16 de agosto de 2008. Dispõe sobre a comercialização de lanches e de bebidas em escolas no âmbito do Estado do Rio Grande do Sul e dá outras providências. Diário Oficial do Estado, Florianópolis, SC, 18 ago. 2008.

RIO GRANDE DO SUL. Secretaria da Educação. Estatísticas da educação. Florianópolis: Secretaria da Educação, 2010.
Disponível em: <http://www.educacao.rs.gov.br/pse/html/ estatisticas.jsp?ACAO=acao1>. Acesso em: 2 mar. 2011.

RODRIGUES, P. A.; MARQUES, M. H.; CHAVES, M. G. A. M.; SOUZA, C. F.; DE CARVALHO, M. F. Prevalência e fatores associados a sobrepeso e obesidade em escolares da rede pública. Ciência \& Saude Coletiva, v. 16, n. 1, p. 1581-1588, 2011. Supl. 1. PMid:21503510. http://dx.doi.org/10.1590/S141381232011000700094.

SÁ, M. A. R. Obesidade infantil X comercialização de alimentos em escolas públicas e privadas. Revista Higiene Alimentar, v. 23, n. 174-175, p. 26-31, 2009.

SANTA CATARINA. Lei n 12.061 de 18 de dezembro de 2001. Dispõe sobre critérios de concessão de serviços de lanches e bebidas nas unidades educacionais, localizadas no Estado de Santa Catarina. Diário Oficial do Estado de Santa Catarina, Florianópolis, SC, 20 dez. 2001.

SÃO PAULO. Portaria Conjunta COGSP/CEI/DSE, de 23 de março de 2005. Normas para funcionamento de cantinas escolares. Diário Oficial do Estado, São Paulo, SP, 24 mar. 2005.

STURION, G. L.; PANCIERA, A. L.; SILVA, M. V. Alimentação escolar: opções de consumo na unidade de ensino. In: SIMPÓSIO LATINO-AMERICANO DE CIÊNCIA DE ALIMENTOS, 6., 2005, Campinas. Anais... Campinas: UNICAMP, 2005.

WILLHELM, F. F.; RUIZ, E.; OLIVEIRA, A. B. Cantina escolar: qualidade nutricional e adequação à legislação vigente. Revista HCPA, v. 30, n. 3, p. 266-270, 2010.

WORLD HEALTH ORGANIZATION - WHO. Global strategy on diet, physical activity and health. Genebra: WHO, 2004. 21 p. Disponível em: <http://www.who.int/dietphysicalactivity/strategy/ eb11344/strategy_english_web.pdf>. Acesso em: 14 nov. 2013.

ZANCUL, M. S.; DAL FABRO, A. L. Escolhas alimentares e estado nutricional de adolescentes em escolas de ensino fundamental.

Alimentos e Nutrição, v. 18, n. 3, p. 253-259, 2007. 